\title{
Schoolchildren determination in Kazakhstan: condition analysis and project suggestions
}

\author{
Saule Kupeshova ${ }^{1, *}$, Almira Zhumagaziyeva ${ }^{1}$, Gulzhihan Smagulova ${ }^{1}$, Yerkezhan \\ Meirkhanova $^{1}$ \\ ${ }^{1}$ Al-Farabi Kazakh National University, 71, Al-Farabi dist., Almaty, Kazakhstan
}

\begin{abstract}
In accordance with data from the labor market formation (nearest past) in Kazakhstan, the prevalence of some jobs over the others can be put into the question. However, the following hypothesis might be stated in advance: do high school students possess a clear vision of current labor market conditions and make their choice consciously with the help of objective information? Judging by the first glance, the hypothesis might be proven false, therefore, a deeper research with respect to both theoretical and empirical evidence is to be analyzed, as is discussed below.Firstly, it should be taken into account, that the question of self-determination has been put into question by various researchers, however, the area remains largely understudied. For example, according to Wrigth, a larger share of schoolchildren demonstrates a tendency towards changing a major for one or more times, however, the explanatory causes of such behavior have been largely uncertain (Wrigth, 2018). It should be noted, that such behavior can be also attributed to Kazakhstan situation, which has further consequences of inappropriate labor market performance. Therefore, the intention of this article is to analyze the situation of schoolchildren determination in Kazakhstan, and to propose potential areas of development. Further, the intention is an attempt to improve the life outcomes of schoolchildren and students via investigation of such factors as major and occupation selection, most important motives and potential outcomes, that could be eventually used for social development, such as higher information policies, enhancement of school and university administration and schoolchildren decisions
\end{abstract}

\section{Introduction}

A number of factors, that could potentially affect decisions made by schoolchildren regarding their major and further labor market activity, are to be identified and taken into account when designing a project. Firstly, it can be hypothesized, that schoolchildren have imperfect information about university majors and labor market structure, which ultimately leads to inefficiencies in labor market itself. This article therefore, intends to examine major choice by schoolchildren through the following four research questions:

- Which factors affect a decision making process for schoolchildren, put simply, how they make a choice of their major and labor market positioning?

\footnotetext{
*Corresponding author: Ardak.Turginbayeva@kaznu.kz
} 
- Whether different major choices are caused by different explanatory factors, either in absolute or in relative terms?

- How do such factors, as the complexity of admission and study process affect the decision making?

- How other factors, such as parents, social pressure or insufficient information influence the decision?

To answer all of this question survey had been conducted.

Personal preferences and tastes of the schoolchildren might be a significant or major determinant of the major choice. With that in mind, the questionnaire proposed below poses a significant attention to questions that might indicate preferences of the schoolchildren in the first place. Other factors, that could be described as more rationale-based, such as expectations of future earnings, labor market constitution and educational abilities were shown to have ambiguous effect on schoolchildren determination, and therefore, were also tried to be identified throughout the questionnaire. The third group of factors, that is mostly hard to measure, such as influence of parents, degree of competiveness and others, were tried to be included into the questionnaire, however, with different degree of potential determination.

It was also found that earning opportunities is not the most important factor, but personal preferences and willingness are important.

Ultimately, this article synthesizes findings from all of the research efforts to develop policy implications that can inform schools and universities seeking to ease the major selection process and help schoolchildren make better major choices, potentially helping them graduate more quickly and at a higher rate, and, eventually, find an occupation that suits them in the mostly favorable way.

\section{Literature review}

It can be stated that schoolchildren make their choices based on a number of reasons, with some part of them being personal or endogenous, whether the other part being determined by a range of exogenous factors. According to the related literature, it can be assumed, that many sources rely mostly on economic factors, including potential effects that schoolchildren may expect to deliver from the labor market. Thus, a study of Beffy, Fougere, and Maurel investigates the effect that potential future earnings may have on the major choice, based on data from France. As a result, the paper concludes, that potential future earnings, that prospective students might expect to deliver from labor market, has small effect on their choice of major at the university. With regard to research questions and hypothesis described for this particular article, the above conclusion might be considered as supportive to the statement of limited or imperfect information that schoolchildren may have regarding the major and labor market.

Another conclusion that was derived from the study described above, states that the decision making process regarding the major choice was in most part driven by noneconomic considerations. Thus Beffy, Fougere, and Maurel point that the abilities of schoolchildren and their attitude towards certain types of school activities were among the most important determinants of the major choice. With regard to the hypothesis stated for this article, it can be assumed that inefficient outcomes for the labor market in Kazakhstan can be improved by emphasizing the rational behavior of schoolchildren, again by eliminating the factor of insufficient information. For sure, personal attributes that schoolchildren possess cannot and should not be dropped out from the decision making process, however, by adding additional information regarding the majors structure and labor 
market constitution might considerably improve the future life outcomes of the schoolchildren (Beffy, 2012).

Another study, written by Wiswall and Zafar, that was trying to investigate the schoolchildren and student determination based on data from New-York University, concludes that for schoolchildren from high income families, who also could have been described as possessing high abilities in education, future potential earnings had a considerable effect on a major choice (Wiswall, 2015).

However, the paper also concluded that in addition to future earnings considerations, schoolchildren tastes and certain aspects, inherent for certain types of majors, such as satisfaction and personal predisposition, were a major determinant of major choice at the university. The above statement supports previous assumption made in this article regarding importance of both rational ad intangible factors determining the choice of major for schoolchildren. In addition, with regard to the research design process, it should be taken into account, that income factor is the one according to which schoolchildren should be differentiated prior to gathering a data.

Another paper, that was trying to identify factors that could potentially influence the major choice for schoolchildren (Arcidiacono, 2004), has investigated that personal preferences and personal abilities of the schoolchildren were important for the decision making process, however, the degree to which such factors could be influential enough to determine the eventual choice of the major, was different for different majors, ranging from relatively small to fundamental.

With regard to the hypothesis and research questions stated for this article, it can be assumed, that determination of schoolchildren willingness to choose certain type of major is to be taken into account at the first place. This step is implemented in the questionnaire that will be described below, representing a primary source of data used for the article.

Another group of authors support previously outlined assumptions regarding the importance of personal preferences of the schoolchildren. In addition to personal preferences, such factors as educational abilities, preparation and future earnings expectations were also shown as having the effect on schoolchildren decision making process (Altonji, 2012).

For example, mathematical abilities were shown to have a significant effect in determining a major choice, whereas verbal abilities were not found to be as influential.

The paper by Reuben, Wiswall, and Zafar further investigated, whether such factors, as the degree of self-confidence and competitiveness of schoolchildren could have an effect on major choice (Reuben, 2015).

Thus, the research has shown small or no effect of the above factors on decision making process, however, it should be taken in to account, that such personal factors might be subject to considerable research bias, and therefore, should not be treated as insufficient at the first place. On the other hand, as such personal factors might be hard to measure and check, their use for the purpose of this particular article could have been questioned, therefore, they were not taken as a part of the questionnaire.

The last but not the least important factor that could potentially have the effect in driving the decision making process of the schoolchildren, is the gender. It can be assumed that preferences regarding certain types of majors might differ significantly for males and females. According to Turner and Bowen, females are more predisposed in their choice towards life and social sciences, while are comparably less interested in more technical majors, such as math, physics, engineering and similar sciences (Turner, 1999). However, it should not be mistaken that males and females are to have different success rates in learning different types of majors, as here we are talking about preferences in the first place. Thus, according to the research by Gemici and Wiswall (Gemici, 2014), which was focusing on National Survey of College Graduates in the US, confirms the previous assumption that males 
and females do not demonstrate significant differences in their learning success and grades, however, do demonstrate a statistically significant difference when talking about major choice preferences. For example, it has been shown, that females demonstrate about onethird less probability of choosing technical sciences or business and finance related majors. According to the research results, it is stated that these differences are led mostly not by differences in skills or cognitive abilities, but rather by different preferences and tastes.

Another study that was focusing on students from New York University, written by Reuben, Wiswall and Zafar, showed, that with no regard to skills and abilities, females are $82 \%$ less likely to choose economics and finance related majors, but $62 \%$ more likely to choose social sciences, when compared to males. In line with arguments that have already been discussed above, it should be taken into account, that small or no differences shown between males and females in their grades irrespectively of the major, might help one to assume that choices led by tastes and preferences might reflect insufficient or wrong information that males and females have about their cognitive abilities. Thus, in case such informational inefficiency exists on the layer of gender, it should be tried to be eliminated, however, by no harming schoolchildren in their tastes and preferences-led choice.

\section{Methodology}

Thus, in order to address the above research questions, both qualitative and quantitative methods were applied. Talking differently, qualitative analysis is useful in determining possible cognitive systems, that affect the decision making process for students, whether quantitative data can be used as a tool for describing and supporting the reasoning made by qualitative analysis above.

Next, the research is relying mostly on primary data source, which is the answers to the questionnaire, proposed to 10-11 schoolchildren in one of the schools located in Kazakhstan's largest city Almaty. Taking into account that local research on such kind of problem is mostly absent, the use of secondary data sources is limited. However, as a starting point, a quick literature review is proposed further in the text.

To inform the policy implications of this work, a scan of policies in place was conducted at the state level regarding major choice, looking for the range of policies in the area and the prevalence of the more common policies. A review was undertaken of school and university policies specific to initial major selection, undecided students, and major switching. Finally, are view of broader policy, including state policies and efforts to encourage students to choose particularly types of majors was also conducted.

\section{Results and Discussion}

The questionnaire of students showed (Table 1) that social orientation and personal preferences largely determine professional self-determination of a person. Certain factors are important to choose a major. They can be divided into endogenous (tastes, abilities, personal preferences) and exogenous (parents, friends, future opportunities, labor market constitution) (Figure 1 and Figure 2).

It should be noted here, that future earnings have not shown themselves to be important determinants of the major choice among schoolchildren, whereas personal preferences and tastes to be a much more considerable factor. Therefore, based on the literature review provided earlier, as well as on results of the questionnaire provided just above, the below SPA project is proposed. 


\section{Exogenous factors}

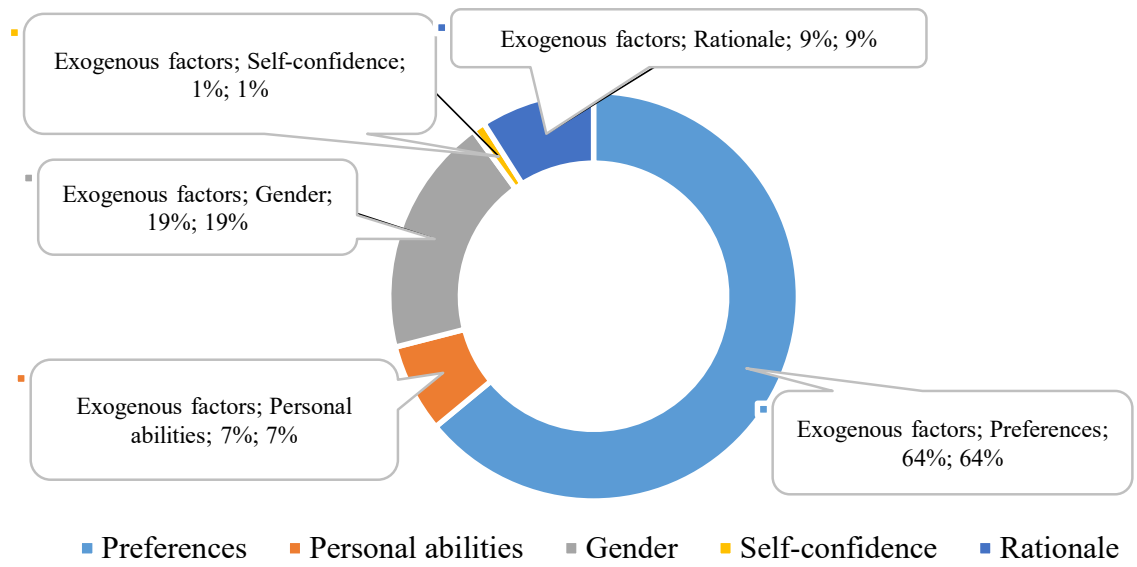

Fig. 1. The results of survey in terms of exogenous factors.

Table 1. The result of survey made to identify factors affecting choice (primary data).

\begin{tabular}{|l|l|l|l|}
\hline \multicolumn{4}{|c|}{ Description of the results } \\
\hline \multicolumn{3}{|c|}{ Exogenous factors } & \multicolumn{2}{c|}{ Endogenous factors } \\
\hline Preferences & $64 \%$ & Parents & $33 \%$ \\
\hline Personal abilities & $7 \%$ & Expected earnings & $7 \%$ \\
\hline Gender & $19 \%$ & Social pressure & $23 \%$ \\
\hline Self-confidence & $1 \%$ & Income & $31 \%$ \\
\hline Rationale & $9 \%$ & Previous preparation & $6 \%$ \\
\hline
\end{tabular}

\section{Endogenous factors}

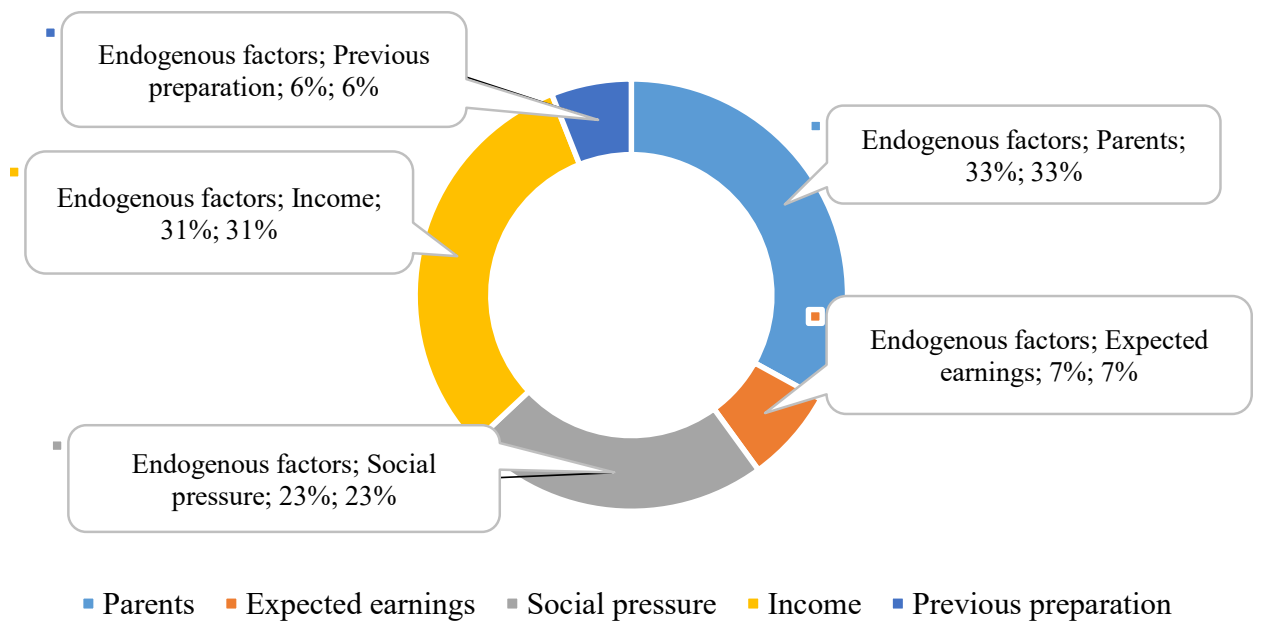

Fig. 2. The results of survey in terms of endogenous factors. 


\section{Conclusion}

It can be assumed that the hypothesis about insufficient information provided for the schoolchildren is one of the main factors that describes the inefficiency of major choice made by schoolchildren. With that in mind, steps of the project are proposed below:

- Provide a constant interaction between representatives of the labor market, universities and school administration, which will result in study sections describing current opportunities and constitution present in the labor market, both domestically and internationally.

- With regard to universities, school administrations should establish a process of reciprocal communication, with the former providing full description of education process, including timing, examinations, admission process and other factors. It is important for such communication, to involve both schoolchildren and their parents.

- With regard to labor market participants, a trilateral communication process might be proposed, including, apart from schoolchildren and their parents, university and school administration representative. It should be noted here, that labor market representatives might position themselves as the initiative side, driving the communication process.

- Apart from educational examinations that determine the admission to universities, additional examination is proposed that will touch upon schoolchildren professional abilities and their personal preferences.

- While designing a project, a significant degree of differentiation is to be take into account, as such factors as income, gender and others have been shown to have a significant differentiating effect both on personal preference of the schoolchildren and their determination regarding the major. For example, the design of the project should take into account, that schoolchildren from higher income families tend to have a more appropriate informational security compared to their lower income peers, therefore, the project should firstly be aimed towards state-sponsored schools and less urbanized areas.

- Provide a process, that will check the durability of the steps described above so that proper changes could be taken as early as possible in order to justify the existence of such program in the first place. It should be taken into account that the evaluation of the project undertaken is a long term process, therefore, a substantialprivate support is needed.

\section{Appendix 1}

Below is the sample questionnaire that was used in the research while preparing the article: Grade: $10 / 11$ Gender: Male/Female

Questionnaire:

1. Do you plan to continue education (university) yes / no

2. If yes, in which of the following groups of specialties would you prefer to continue your education?
a. IT
b. Energy
c. Economics and Finance
d. Law
e. Healthcare
f. Education
g. Other

3. If no, have you already chosen a specialty for work, and in what area?

4. What influenced your choice of your desiredmajor in the most significant way? 

a. Parents
b. Expected earnings
c. Reviews of friends / relatives
d. The preferences of friends / others
e. Other

5. What do you think has shaped / will shape your choice of profession to a greater extent? Need / desire

6. In your opinion, do you need additional support for continuing education? Yes / no

7. Do you plan to receive further education in Kazakhstan / neighboring countries / non-CIS countries?

8. If yes, what do you think, does your choice of profession correspond to the predicted distribution of state. and internal higher education grants?

9. If no, which of the following reasons is most appropriate for your choice of a foreign education?
a. The desire of parents / relatives
b. Better prospects for further career growth
c. Other

10. If there is no opportunity to continue education / work in the desired / chosen specialty, which of the groups of specialties is most suitable for you as an alternative?
a. IT
b. Energy
c. Economics and Finance
d. Law
e. Healthcare
f. Education
g. Other

\section{References}

1. David G.C., Kamel M, Wayne F.C., J O M, 'Global Talent Management and Performance in Multinational Enterprises: A Multilevel Perspective', Vol. 45(2), 540-566, 2018

2. Rumney A, New Directions in Vocational Education, Routledge, $5^{\text {th }}$ Edition, 114-120, 2019.

3. Meyers M, Woerkom M, Paauwe J, Dries N, T I J O H R M, 'HR managers' talent philosophies prevalence and relationships with perceived talent management practices.', Vol.5, 31-37, 2019

4. Wrigth, C., "Choose Wisely: A Study of College Major Choice and Major Switching Behavior", RAND, 56-57, 2018

5. Beffy, M., Fougere, D. ,Maurel, A., T R O E S, "Choosing the Field of Study in Postsecondary Education: Do Expected Earnings Matter?", vol. 94 (1)., 334-347, 2012

6. Wiswall, M., Zafar, B., R o E S, "Determinants of college major choice: Identification using an information experiment, Vol. 82, No. 2 (291), 791-824,2015

7. Arcidiacono, P.,J O E,"Ability sorting and the returns to college major".,vol. 121., 343375,2004

8. Altonji, J.G., Blom, E., Meghir, C,A R O E,"Heterogeneity in Human Capital Investments: High School Curriculum, College Major, and Careers", vol. 4. Pp. 185223,2012 
9. Reuben, E., Wiswall M., Zafar, B., E J, "Preferences and Biases in Educational Choices and Labor Market Expectations: Shrinking the Black Box of Gender", Vol 127(604), 2153-2186, 2015

10. Turner, S. and Bowen, W., I A L R R, "Choice of Major: The Changing (Unchanging) Gender Gap"., vol. 52 (2)., 289-313, 1999

11. Gemici, A. and Wiswall, M.,I E R, "Evolution of Gender Differences in Post-Secondary Human Capital Investments: College Majors at the Intensive Margin", vol. 55 (1). , 23 56,2014

12. Azbel A., P PP, Statusiprofessional'noiidentichnosti. (Oprosnik), [Professional determination statuses (Questionnarie)],p.23.,2005

13. DanilyukO., Shaydurova V. P M M E, Podgotovkauchenikov k viboruprofessiy. [Preparation of students to make professional choice]. №1, 150, 2014

14. Dow, J.C.R. and L.A.Dicks-Mireaux, O E P, 'The Excess Demand for Labour, A Study of Conditions in Britain, 1946-56', Vol 10(1), P.1-33, 1958

15. Ericsson E., Identity: Youth and Crisis, 2nd edition, 157, 1996

16. Habib M. Fardoun, Abdullah A, P O T F C C S A I S, New Teaching Methods: Merging "John Dewey" and "William Heard Kilpatrick" Teaching Techniques, 803-808, 2014

17. Jack R. Meredith, Samuel J. Mantel Jr., Project Management: A Managerial Approach, 8th Edition, 215, 1998

18. Martin P and Tate K, W T B, Project management, A managerial approach, 5th Edition, 31-32, 2002 